Titulo do Trabalho

\title{
COWORKING: CONTRIBUIÇÕES DE UM MODELO DE CONSUMO COLABORATIVO E DA ARQUITETURA CORPORATIVA PARA O GERENCIAMENTO DAS CIDADES
}

\author{
Nome da Autora Principal \\ Claudia Maria Neme dos Santos \\ E-mail de contato \\ claudianeme.arq@gmail.com
}

Palavras-Chave

Coworking. Arquitetura Corporativa. Sustentabilidade.

\section{INTRODUÇÃO}

O aumento dos custos sociais e empresariais no mundo contemporâneo, bem como a crescente preocupação com a sustentabilidade, a qualidade de vida e os desafios impostos pelas grandes concentrações urbanas, fortaleceram, nas ultimas décadas, a necessidade da busca de soluções criativas para o planejamento das cidades, considerando a mobilidade, a preservação e o conforto ambientais. As crises financeiras observadas nas ultimas décadas e os problemas gerados pelo novo modelo econômico do mundo globalizado, estabelecendo o consumo como estilo de vida, levaram a importantes impactos ambientais e sociais. A insatisfação e a frustração das pessoas, cuja felicidade e status social foram atrelados ao consumo desenfreado, motivou reflexões sobre a impossibilidade de acompanhar o crescente lançamento no mercado de novos produtos, serviços 

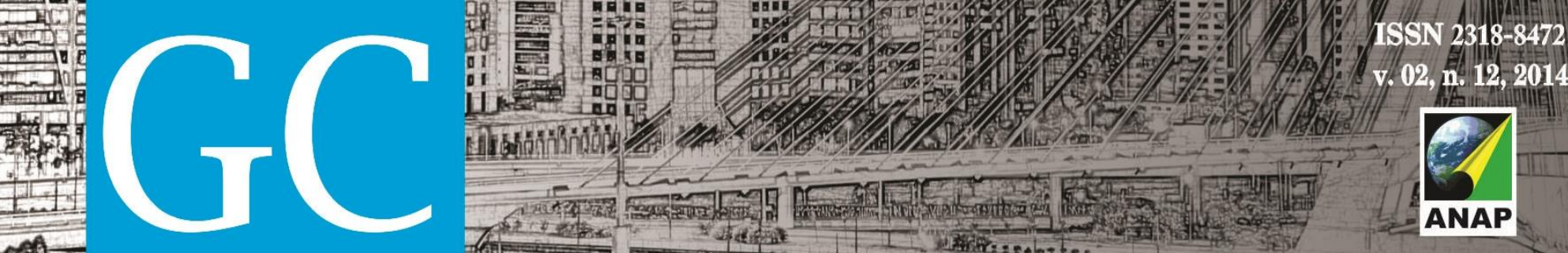

Revista Nacional de

Gerenciamento de Cidades

e bens e sobre a necessidade de se repensar as questões de consumo e de estilo de vida, especialmente nas grandes cidades (SILVA, 2013).

A concepção de sustentabilidade, lançada a publico em 1987 destaca, entre suas matrizes, a pretensão de combater o desperdício material gerado pelo desenvolvimento, alem de propor limites ao crescimento econômico e à pressão por ele exercida sobre os recursos ambientais. Para Herculano (1992), o conceito de desenvolvimento sustentável, formalizado pelos ambientalistas, vem, segundo estes, sendo distorcido, o que pode ofuscar seu verdadeiro significado, ou seja, a ideia de mudanças substanciais nos processos de produção e consumo. e a retomada de interesses sociais coletivos. Para alguns de seus teóricos e analistas, o conceito de desenvolvimento sustentável, propõe a substituição de um paradigma ineficaz e esgotado, por uma nova filosofia de desenvolvimento econômico (COSTA LIMA, 1997).

O conceito de consumo colaborativo em delineamento nos últimos anos, fortaleceu-se consideravelmente a partir da constatação de graves problemas representados pelo lixo urbano, insuficiência dos transportes públicos, os grandes congestionamentos de transito, a falta ou inadequação do planejamento das cidades, dentre outros desafios socio-ambientais. Neste contexto, o conceito de consumo colaborativo se popularizou na Europa, Estados Unidos e outros países ocidentais; representando uma busca por novas formas de acesso a bens e serviços, de forma racional, econômica, colaborativa e sustentável, colaborando para a solução de importantes desafios dos modelos econômico e urbano atuais (BOSTMAN e ROGERS, 2011).

O consumo colaborativo constitui-se um movimento focalizado no conceito de compartilhamento, que ressalta o senso de comunidade e resgata praticas sociais cooperativas. Possibilita aquisições e o uso de bens, espaços e serviços de forma coletiva, como compras, locações, uso compartilhado de espaços de trabalho, de transporte e de transportes alternativos, dentre outras iniciativas inovadoras. Apresentam-se, hoje, alguns novos modelos, considerados mais econômicos e capazes de facilitar a mobilidade urbana, a 


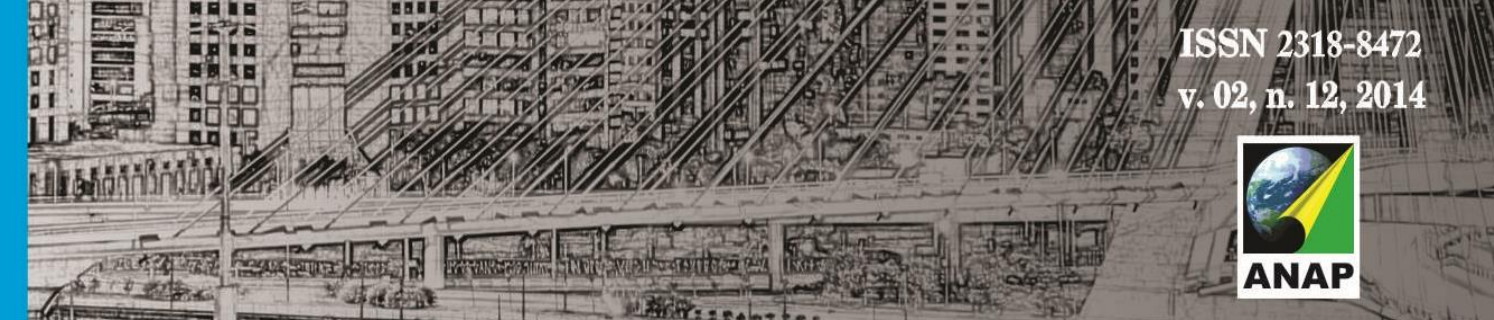

Revista Nacional de

Gerenciamento de Cidades

redução da perda de tempo em grandes congestionamentos, a redução das grandes distancias entre a moradia e o trabalho e a racionalização de despesas e de consumo.

No Brasil, embora ainda não seja muito conhecido, o conceito de consumo colaborativo vem se firmando progressivamente. Silva (2013), descreveu e avaliou um serviço de compartilhamento de bicicletas existente na cidade de Porto Alegre, concluindo pelo sucesso e boa aceitação do serviço pela população, a despeito da necessidade de algumas melhorias no serviço, sugeridas pelos usuários. Neste trabalho, Silva ressalta a necessidade de disseminação do conceito de consumo colaborativo e os benefícios do consumo consciente. Apresenta algumas sugestões de consumo colaborativo, dentre as quais o modelo de coworking, alertando para o fato de que o estilo de vida consumista e o consumo desmedido, especialmente nos países desenvolvidos, não poderão ser sustentados por muito tempo.

Ao possibilitar o compartilhamento de espaços, de infraestrutura física e tecnológica e de serviços, o coworking é um dos exemplos de consumo colaborativo já existente no Brasil, permitindo a redução de despesas, facilitando a mobilidade urbana e maximizando a eficiência e a produtividade no trabalho. As atuais exigências de economia de tempo, de agilidade na comunicação e de aumento da produtividade, aliadas às facilidades introduzidas pela internet e outros avanços tecnológicos, mudaram o conceito de espaço corporativo e se transformaram em grande desafio na área da Arquitetura Corporativa (ABASCAL et al., 2008).

Segundo Gomes (2013), surge atualmente, uma variedade de conceitos e tendências alternativas de espaços corporativos que visam flexibilizar o ambiente e as relações de trabalho, alem de resultar em maior economia de tempo e de investimentos a empresários e trabalhadores em geral. Tais espaços oportunizam a integração e a colaboração entre pessoas e grupos que atuam de forma independente e em diferentes negócios, mas que desejam trocar experiências e trabalhar de forma menos isolada e mais criativa. $O$ 


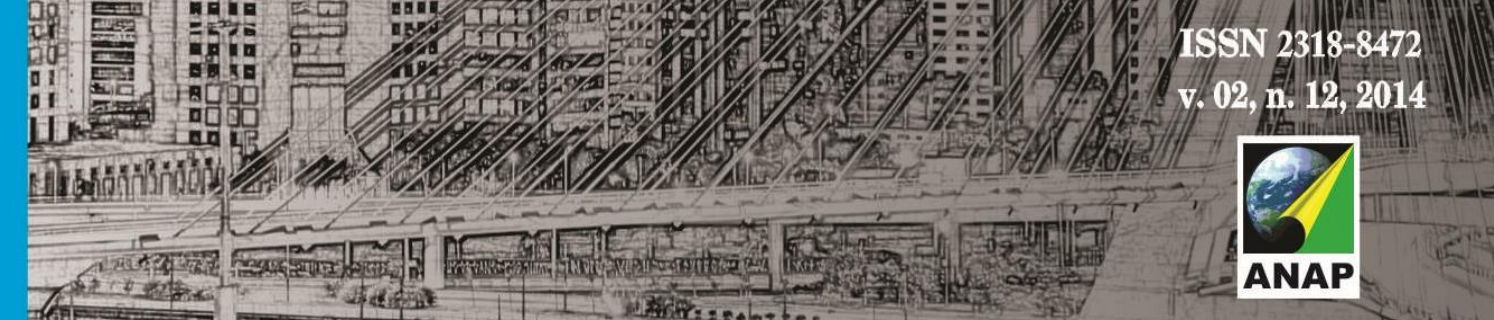

Revista Nacional de

Gerenciamento de Cidades

\section{METODOLOGIA}

Realiza-se, no presente trabalho, um estudo de caráter exploratório sobre o conceito de coworking, caracterizado como um modelo alternativo no campo da Arquitetura Corporativa. A pesquisa exploratória, segundo Gil (1999), busca conhecer em maior profundidade um determinado assunto ou tema, procurando clarifica-lo. Para Gil, o estudo exploratório visa obter um panorama geral sobre um fenômeno ou tema, com base no material já publicado encontrado, principalmente quando o tema escolhido ainda se encontra pouco explorado. Para isto, segundo Gil, a pesquisa exploratória inclui o estudo bibliográfico, visando identificar e revisar a literatura pertinente disponível.

Dentre as principais finalidades da pesquisa exploratória, encontram-se a busca por maiores informações sobre 0 assunto proposto para investigação e a identificação de novos enfoques sobre o assunto, conforme esclarece Andrade (2002), ao abordar o método exploratório de pesquisa, descrevendo-o de modo concordante com o explicitado por Gil (1999) a respeito deste método.

Desta forma, para a elaboração do presente trabalho foi efetuada uma pesquisa bibliográfica assistemática, incluindo livros, artigos publicados em periódicos e encontrados na internet, a partir das palavras-chave: coworking, consumo colaborativo, arquitetura corporativa, escritórios compartilhados, sustentabilidade e desenvolvimento sustentável. O material obtido foi selecionado de acordo com sua pertinência e relevância frente aos objetivos propostos.

\section{RESULTADOS}

O coworking é abordado no material bibliográfico consultado, como um modelo corporativo emergente, capaz de sintetizar as novas necessidades e demandas do mundo do trabalho no século XXI e, consequentemente, as novas exigências feitas ao campo da Arquitetura Corporativa atual. Representa 


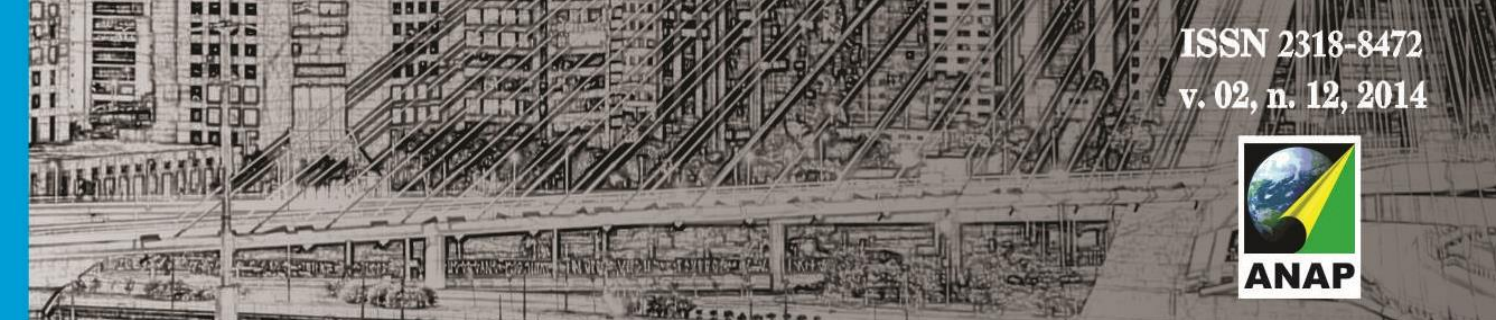

Revista Nacional de

Gerenciamento de Cidades

uma forma de consumo colaborativo que prioriza a sustentabilidade e a redução de custos, descentraliza os locais de trabalho, viabiliza a pratica de atividades remotas, incrementa a produtividade e permite o compartilhamento de áreas estrategicamente localizadas por diferentes empresas e profissionais independentes.

Coworking, é um nome geralmente atribuído a escritórios compartilhados que surgiu para atender demandas atuais no contexto dos novos modelos empresariais e de organização do trabalho, bem como, contribuir para o desenvolvimento de novas configurações urbanas, na busca de soluções para os problemas gerados pelo modelo econômico em vigor. O termo surgiu no Vale do Silício, quando empreendedores do ramo da tecnologia abriram um apartamento para oferecer um espaço de trabalho para pessoas que necessitavam desse espaço porque não o tinham.

Os primeiros escritórios virtuais, Hubs e escritórios de coworking surgiram nos Estados Unidos nos últimos anos para responder a uma nova e crescente demanda por espaços alternativos e diferenciados de trabalho (HECKLER, 2012). O conceito evoluiu, ressaltando o potencial do coworking como fator de racionalização do consumo, local de compartilhamento de ideias e experiências, recurso facilitador da redução de tempo perdido em grandes congestionamentos urbanos, bem como, abarcando a busca de respostas para importantes problemas das grandes cidades e referentes à sustentabilidade.

Os ambientes profissionais compartilhados coworking permitem que se trabalhe ao lado de outros profissionais, com redução significativa de custos operacionais e tendo disponíveis, no mesmo ambiente, recursos como telefones, internet, recepcionista, fax, copiadoras, dentre outras comodidades tecnológicas, além de infraestrutura necessária para o desempenho de diferentes atividades de trabalho. A proposta é reunir profissionais e empreendedores de diversas áreas em um espaço colaborativo, garantindo a infraestrutura básica para que conduzam seus negócios, alem da oportunidade 


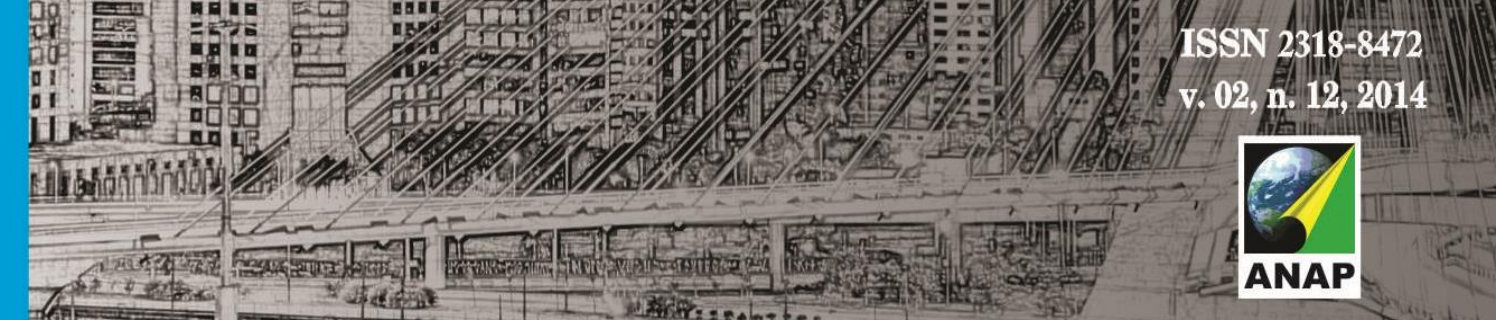

Revista Nacional de

Gerenciamento de Cidades

para a comunicação e a troca de ideias, de acordo com o conceito de networking (CASHMAN, 2000).

Os modelos atuais de escritórios corporativos compartilhados variam, com opções como o Escritório Virtual, que incluem recebimento de correspondências e atendimento telefônico, como também a opção de contar com espaços físicos diversificados como salas de reuniões, salão de eventos, salas individuais, salas coletivas, área de descanso, café, entre outros espaços. A localização descentralizada destes tipos de escritório é fundamental para o sucesso da atividade, em consonância com sua ênfase no conceito de consumo colaborativo e sustentável, contribuindo para melhorar a qualidade de vida nos grandes e médios centros urbanos. Este é um segmento em expansão e tem alcançado bons resultados, tanto em situações de crise, quando as empresas procuram diminuir custos, quanto em fases de crescimento econômico, nas quais há expansão dos negócios (LOPES, 2009).

Observa-se, no mundo todo, grande evolução e aumento da procura por alternativas de consumo colaborativo e de espaços de trabalho coletivos, sendo que o Brasil é um desses interessados nos escritórios compartilhados (SILVA, 2013). Em 2012, o The New York Times, em sua primeira edição impressa, publicou um artigo sobre as mais importantes tendências do mundo do trabalho. O modelo de coworking foi classificado como "fenômeno" e apontado como uma tendência que deve se ampliar ainda mais.

A nova maneira de conceber o trabalho que emerge no século $X X I$ impõe uma mudança de mentalidade que incorpore a necessidade de colaboração de nossa época. As redes sociais são frutos deste movimento e representam essa tendência. Cada vez mais desenvolvemos novos trabalhos e negócios com pessoas de diferentes lugares, profissões e momentos. $O$ coworking faz parte dessa mudança de mentalidade, permitindo, por sua flexibilidade, que as pessoas se conectem e interajam com diferentes talentos com formações profissionais diferentes (GONÇALVEZ, 1997). 

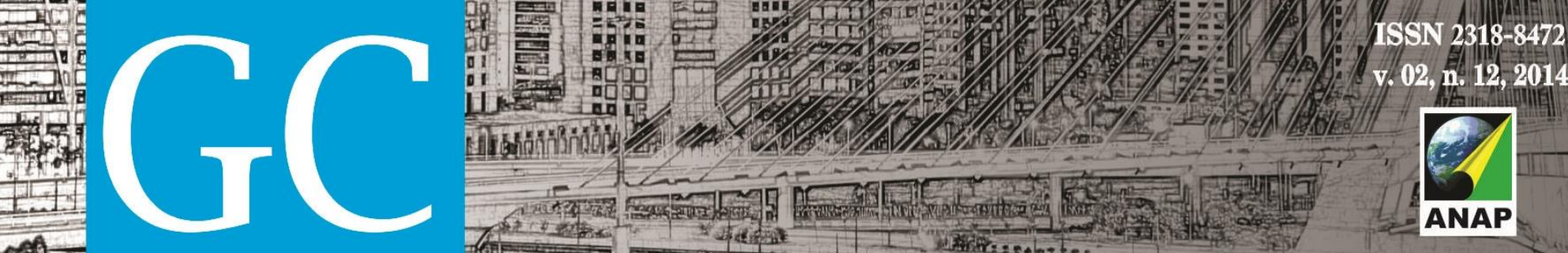

Revista Nacional de

Gerenciamento de Cidades

Como manifestação desta nova cultura e linguagem, cresce a procura por essas novas formas, espaços e ferramentas que tem, paralelamente, criado novas comunidades que, por sua vez, criam uma nova cultura e uma nova linguagem. Esses espaços favorecem a criatividade de cada pessoa e a elaboração de novas idéias e projetos, emoldurando uma nova cultura, substituindo praticas consumistas e depredadoras do meio ambiente. $O$ coworking está em sintonia com o espírito do nosso tempo (SANTOS, 2013).

O coworking não é apenas o compartilhamento de um espaço físico, mas visa a construção de redes dinâmicas entre pessoas com pensamento similar que, ao trocar experiências podem co-criar novos projetos. Seus espaços permitem a multifuncionalidade, podendo representar uma boa opção para empresas e empresários que compartilham alguns valores pertinentes ao conceito de coworking, tais como os de colaboração, comunidade, abertura, sustentabilidade e acessibilidade, citados por Kwiatkowski e Buczynski (2011).

Ao redefinir a forma de relação entre o profissional e seu ambiente de trabalho, o coworking como um novo conceito de ambiente corporativo, apresenta-se como um modelo alternativo ao home-office e ao escritório tradicional. Substitui as grandes torres de edifícios comerciais que foram considerados um grande ícone do século XX, mas cuja imponência passou a ser questionada, tanto pelo ponto de vista estético, quanto pelo seu impacto no meio urbano. As mega torres de escritórios constituíram-se verdadeiras cidades dentro das cidades e tem produzido impactos significativos no planejamento urbano, alem de riscos, tanto do ponto de vista construtivo, como no acumulo de transito e no sombreamento excessivo de seu entorno, alem de interferir na qualidade de vida (VARGAS, 2003; ANDRADE, 2007).

As grandes obras, os edifícios majestosos, agem como elementos promocionais da administração publica e são utilizados com objetivos eleitoreiros, atuando como grandes vitrines e como fator promocional das cidades, competindo entre si. Para Abascal et al. (2008), as modificações na dinâmica produtiva observadas a partir da década de oitenta do século $\mathrm{XX}$, 


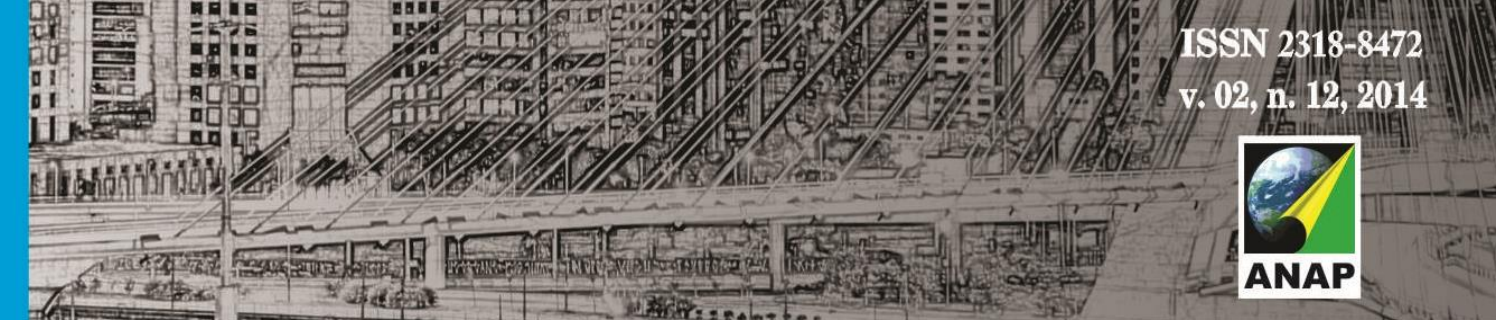

Revista Nacional de

Gerenciamento de Cidades

provocaram um realocamento das atividades corporativas, que transformou a paisagem urbana. Grandes áreas concentradoras de atividades de serviços sediadas em edifícios corporativos foram construídas, enfatizando-se o edifício, e não a totalidade do espaço concebido, desconsiderando a importância da qualidade do ambiente urbano._Segundo Vargas (2003), a cidade passa a ser pensada como produto para turistas, investidores, empresas e consumidores e, assim, a arquitetura e o desenho urbano passam a refletir o capital, numa cultura de consumo, o que vem sendo mundialmente questionada e criticada.

A tendência atual é a construção de edifícios de escritórios colaborativos de menor porte, descentralizados, ecologicamente adequados, energeticamente eficientes, introduzindo espaços híbridos que valorizam a qualidade de vida física e psicológica dos usuários. A criação de ambientes funcionais adaptados às exigências de economia de tempo, à busca de agilidade e sustentabilidade, à facilidade de comunicação e às necessidades da imagem empresarial, tornou-se um dos principais desafios da Arquitetura Corporativa. Este ramo da Arquitetura ampliou suas funções, passando a ser fundamental nos resultados e lucratividade das empresas, bem como agregando novos conceitos e valores, correspondentes às novas concepções de escritórios corporativos, tais como a concepção do coworking, com impactos significativos na característica das cidades.

Para Andrade, C.M.A. (2007), as edificações corporativas atuais devem ser projetadas segundo critérios específicos de quem vai ocupá-las, ao contrario dos projetos corporativos resultantes do distanciamento entre 0 empreendedor e o usuário, focados apenas no potencial de mercado da região e nos objetivos de locação e venda a terceiros Dessa forma, a Arquitetura Corporativa do século XXI, procura levar em consideração as inovações tecnológicas, as crescentes necessidades de humanização, além da preocupação com a imagem e a qualidade ambiental dos edifícios, tanto para seus usuários como para o meio urbano. 


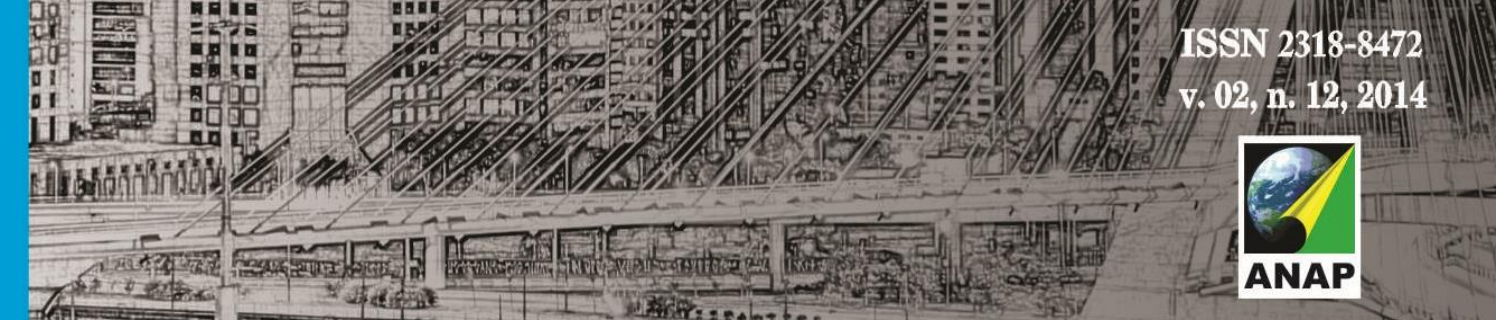

Revista Nacional de

Gerenciamento de Cidades

À medida que o coworking ganha força, o movimento se expande e redefine o escritório tradicional em termos de espaço físico, de conceitos e de valores. As necessidades e condições de trabalho já mudaram muito e continuam mudando. Cada vez mais há um afastamento da idéia de um local fixo e centralizado de trabalho, para onde se vai de segunda a sexta-feira, permanecendo por oito horas ou mais nesse local. Para Hibbert, Kimble e White (2010), os estudiosos dessas novas tendências afirmam que ainda ocorrerão muitos avanços e que muitas pessoas, em futuro próximo, vão poder escolher como e onde trabalhar.

Neste sentido, considerando as tendências contemporâneas que propõem mudanças nos hábitos de consumo, maior consciência no uso de recursos econômicos e naturais, transformações nas formas de organização do trabalho, necessidade de planejamentos urbanos que considerem valores como acessibilidade, mobilidade e sustentabilidade, bem como a necessidade de mudanças de paradigmas, de mentalidades e de estilo urbano de vida, o coworking, ao abarcar estas demandas, evidencia-se como importante modelo a contribuir para as mudanças em curso.

\section{CONSIDERAÇÕES FINAIS}

Ao se apresentar como um novo paradigma no conceito de trabalho e na Arquitetura Corporativa, o coworking pode ser considerado um modelo inovador e transformador da realidade urbana. Constitui-se tendência em evolução na Arquitetura brasileira e internacional, por sua flexibilidade e mobilidade. Incrementa o rol de soluções criativas possíveis para responder às demandas sociais, ambientais e urbanas contemporâneas. Sugere-se que 0 coworking pode auxiliar na minimização de questões como a mobilidade urbana, o confinamento das pessoas num trafego congestionado, a centralização de empresas e profissionais em mega e dispendiosos edifícios corporativos e o excessivo consumo individual. 
